\title{
Behavioural significance of prolactin signalling in the central nervous system during pregnancy and lactation
}

\author{
David R. Grattan \\ Department of Anatomy and Structural Biology, School of Medical Sciences and \\ Neuroscience Research Centre, University of Otago, Dunedin, New Zealand
}

\begin{abstract}
The role of prolactin in the regulation of mammary gland development and function during pregnancy and lactation is well established. However, in addition, prolactin appears to have a much wider role in the physiology of lactation. There is widespread expression of prolactin receptors in the hypothalamus during lactation, indicative of a multi-faceted role for prolactin in regulating hypothalamic function. During pregnancy and lactation, the maternal brain undergoes structural and functional modification, allowing the establishment of appropriate behaviour to feed and nurture the offspring, to adjust to the nutritional and metabolic demands of milk production, and to maintain appropriate hormone secretion to allow milk synthesis, secretion and ejection. The coordination of such a range of neurobiological and neuroendocrine adaptations requires an endocrine signalling mechanism, capable of communicating the reproductive state to the brain. Evidence indicates that prolactin is part of this mechanism.
\end{abstract}

Prolactin is required for lobuloalveolar development in the mammary gland during pregnancy, for lactogenesis at parturition, and for the ongoing maintenance of milk secretion during lactation (Tucker, 1994). There is increasing evidence that prolactin also exerts important actions in the central nervous system (CNS) during pregnancy and lactation. In mammals, successful reproduction requires a wide range of adaptations to occur in the mother. Maternal homeostatic regulators are set at new levels, to allow the mother to cope with the metabolic, physiological and physical demands of the pregnancy. Maternal commitment to reproduction continues beyond gestation, and involves the establishment of lactation and appropriate maternal behaviour. Most of the physiological and behavioural changes that occur during pregnancy and after birth are dependent upon adaptive changes that take place in the brain of the mother, driven by the hormonal changes that occur during these periods. Multiple neuronal systems are involved and co-ordination of such a broad range of neuronal systems is well suited to an endocrine signalling mechanism. This review describes the multiple changes that occur in the neuroendocrine regulation of prolactin secretion during pregnancy and lactation that result in a prolonged state of hyperprolactinaemia, and discusses the hypothesis that this hyperprolactinaemia provides the afferent signal required by the brain to register the reproductive state, allowing the organization and coordination of a wide range of behavioural and neuroendocrine adaptations in the maternal brain.

Email: dave.grattan@anatomy.otago.ac.nz

\section{Changes in neuroendocrine regulation of prolactin secretion during pregnancy and lactation}

Prolactin secretion is predominantly under the inhibitory control of dopamine, which is produced by the tuberoinfundibular dopamine (TIDA) neurones located in the arcuate nucleus of the hypothalamus (Freeman et al., 2000). Dopamine is released from nerve terminals in the median eminence and then transported in the blood to the pituitary gland via the hypophyseal portal vessels. Dopamine activates D2 receptors on pituitary lactotrophs to inhibit tonically prolactin secretion (Fig. 1). Prolactin acts in a short-loop feedback manner to regulate its own secretion by stimulating the TIDA neurones (Freeman et al., 2000). Prolactin action on TIDA neurones is mediated directly by prolactin receptors expressed on these neurones (Grattan, 2001), activating the JAK-STAT signalling cascade (see Box 1 for details). The interactions between dopamine and prolactin are further illustrated by gene disruption experiments. Chronic elevation in prolactin secretion occurs in mice lacking a functional D2 dopamine receptor (Kelly et al., 1997) due to an absence of inhibition in the pituitary gland. Similarly, serum prolactin concentrations are markedly increased in prolactin receptor-deficient mice (Kelly et al., 2001), presumably due to lack of feedback stimulation of TIDA neurones.

The vital role played by prolactin during pregnancy and lactation is emphasized by the physiological changes that occur in the mother to maintain a prolonged state of hyperprolactinaemia. There are at least three major changes in the regulatory pathways controlling prolactin secretion during pregnancy and lactation. First, the placenta provides 


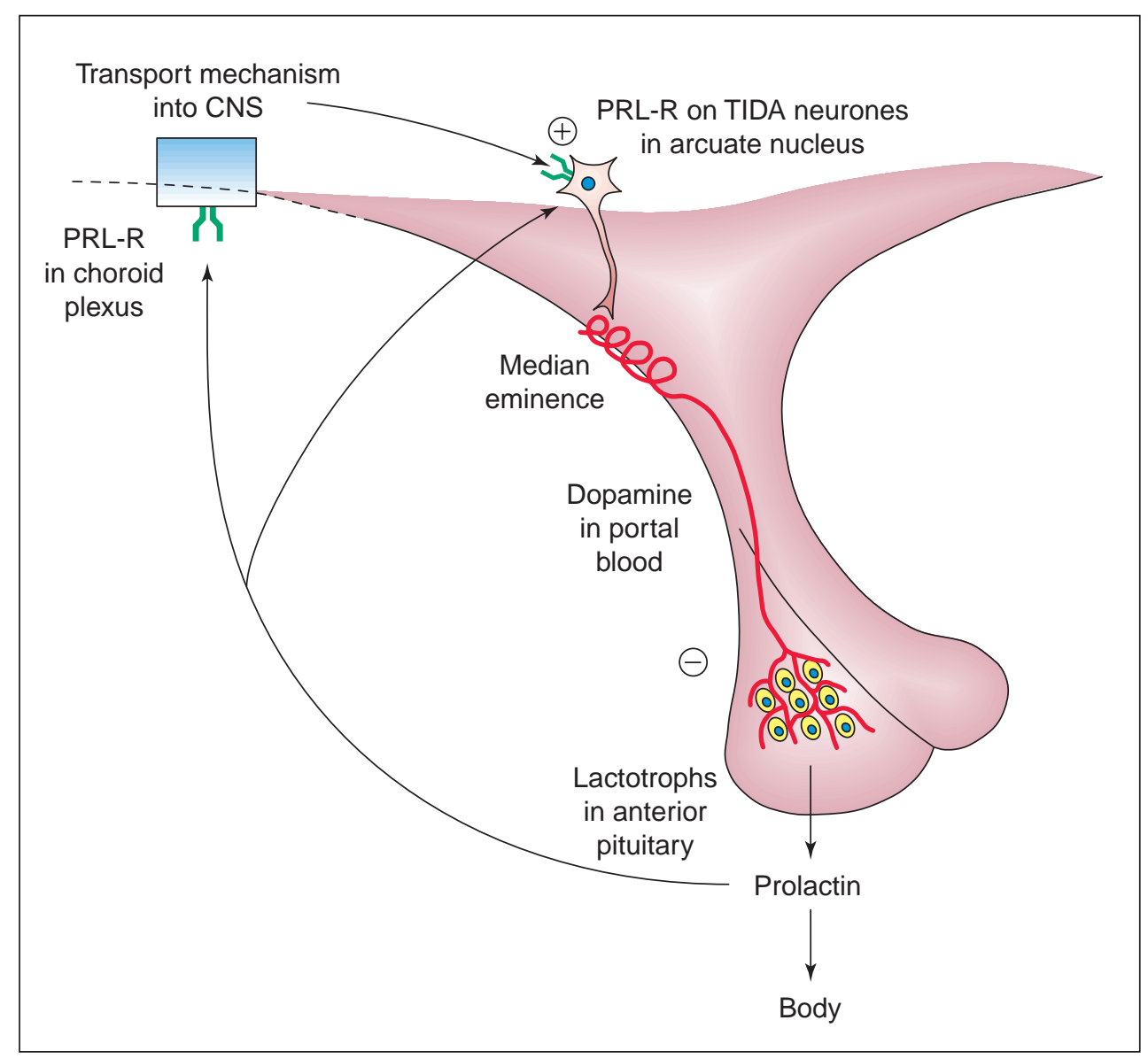

Fig. 1. Regulation of prolactin secretion by short-loop negative feedback. Prolactin secretion is tonically inhibited by the hypothalamus by means of dopamine secreted in the median eminence from the tuberoinfundibular dopaminergic (TIDA) neurones. Prolactin then regulates its own secretion by stimulating prolactin receptors (PRL-R) on the TIDA neurones. Prolactin may access these neurones directly through fenestrated capillaries in the median eminence, or after entering the central nervous system (CNS) via a carrier-mediated transport mechanism in the choroid plexus.

a source of circulating lactogenic hormones in many species (Soares et al., 1998). Placental lactogen activates prolactin receptors, but its secretion is not subject to the normal negative feedback control that limits prolactin secretion from the maternal pituitary gland. Hence, the short-loop feedback system is bypassed during pregnancy, ensuring the continued presence of a hormone capable of activating the prolactin receptor throughout pregnancy (Fig. 2). Second, during late pregnancy, the TIDA neurones show a reduced ability to respond to prolactin (Grattan and Averill, 1995; Andrews et al., 2001), and pituitary prolactin secretion resumes even in the ongoing presence of placental lactogen. This impaired negative feedback continues into lactation (Arbogast and Voogt, 1996) allowing the maintenance of high prolactin secretion, unopposed by a regulatory feedback mechanism (Fig. 3). Finally, with the onset of lactation and maternal behaviour, suckling of the nipple by the neonate provides a powerful prolactin stimulus. This involves a suckling-induced decrease in TIDA neuronal activity (Selmanoff and Gregerson, 1985), possibly coupled with the release of one or more prolactinreleasing factors (Neill and Nagy, 1994). Together, these changes result in a prolonged period during which the body (and brain) is exposed to high concentrations of prolactin. Clearly, these adaptations are critical for development and maintenance of mammary gland function during pregnancy and lactation. However, the prolonged hyperprolactinaemia resulting from these adaptations also has important implications for prolactin effects on the brain.

\section{Access of prolactin to the brain}

For prolactin of systemic origin to regulate hypothalamic function, there must be a mechanism for prolactin to enter the CNS. As prolactin is a relatively large polypeptide hormone (197-199 amino acids), it would be expected to 


\section{Box 1. Prolactin signal transduction in tuberoinfundibular dopaminergic neurones}

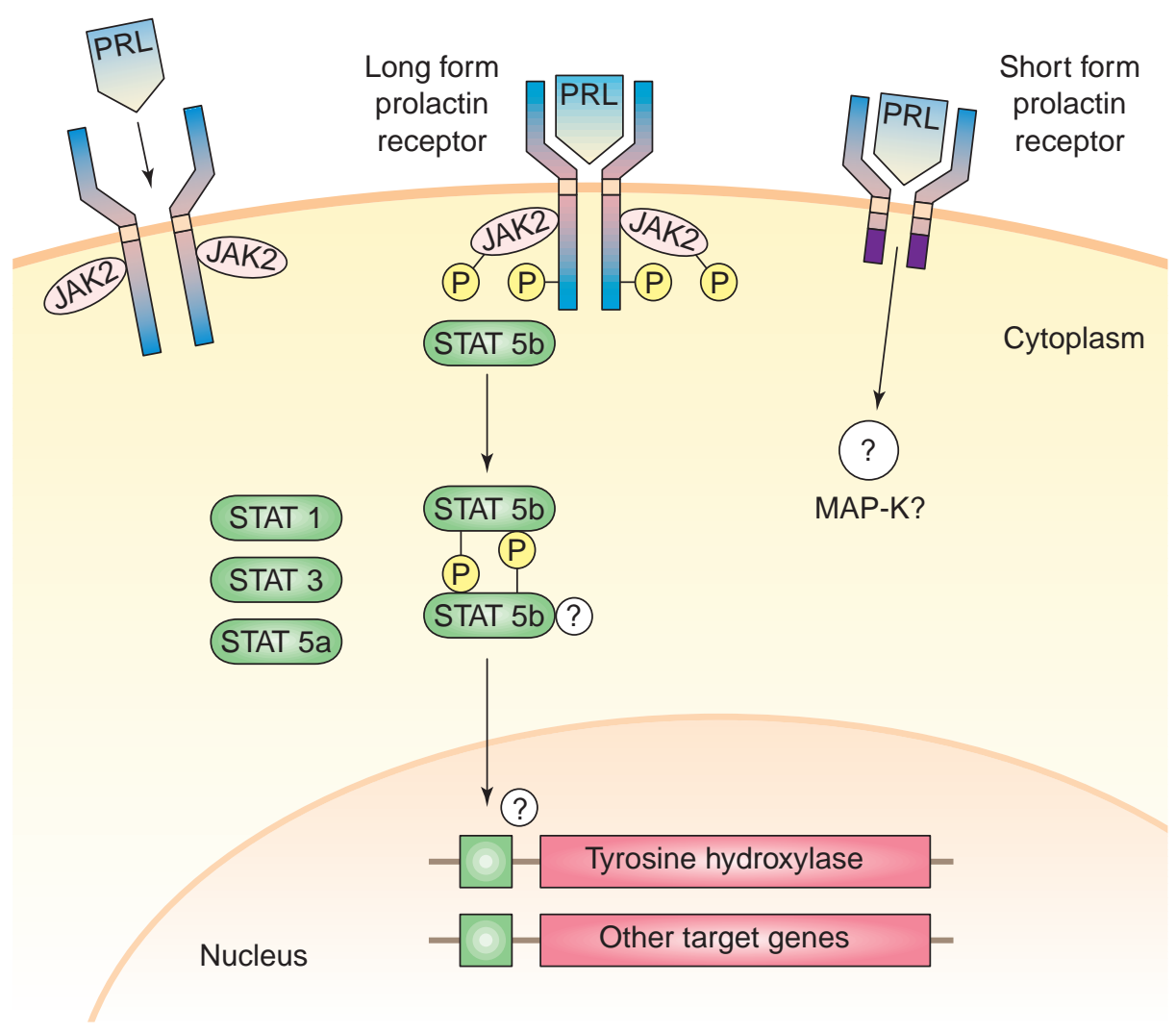

The prolactin (PRL) receptor is a member of the class 1 cytokine receptor superfamily (Bole-Feysot et al., 1998). There are at least two isoforms of the prolactin receptor molecule, a long form and a short form, produced by alternative splicing of the prolactin receptor gene. The different isoforms of the receptor protein have not been specifically identified within brain tissue, but several studies have examined the distribution of the two forms of prolactin receptor mRNA (Bakowska and Morrell, 1997; Pi and Grattan, 1998a). Both forms are highly expressed in the choroid plexus, but the long form is predominant in the hypothalamus. The two forms of the prolactin receptor have identical extracellular portions, and so are both able to bind prolactin, but differ in their ability to activate intracellular signalling pathways. Binding of prolactin to its receptor induces dimerization of the receptor molecules, and then activation of multiple intracellular signalling proteins (Bole-Feysot et al., 1998; Freeman et al., 2000). Ligand interaction with the long form of the receptor leads to phosphorylation (P) of the receptor associated Janus tyrosine kinase 2 (JAK2). JAK2 recruits and phosphorylates a family of latent cytoplasmic proteins known as signal transducers and activator of transcription (STATs). Phosphorylated STAT molecules form homo- or hetero-dimers, translocate to the nucleus and bind to specific promoter sequences of target genes (Leonard and O'Shea, 1998). In various tissues, several STAT are involved in prolactin signal transduction, including STAT1, STAT3, STAT5a and STAT5b (Bole-Feysot et al., 1998). In the tuberoinfundibular dopaminergic (TIDA) neurones, prolactin treatment induces nuclear translocation of STAT5 (Lerant et al., 2001). Furthermore, STAT5b-deficient mice have extraordinarily high concentrations of serum prolactin, which appear to arise from a failure of prolactin signalling in the TIDA neurones (Grattan et al., 2001). These data indicate that STAT5b specifically mediates the negative feedback action of prolactin on TIDA neurones, although other STAT proteins may form heteromeric dimers with STAT5b. As only the long form of the receptor can activate the JAK-STAT pathway, involvement of STAT5b in the prolactin regulation of TIDA strongly implicates the long form of the receptor as the critical protein mediating prolactin signal, at least in this population of neuroendocrine neurones. Although the short form of the receptor cannot activate the JAK-STAT pathway, it can mediate some actions of prolactin through the mitogenactivated protein kinase (MAP-K) pathway (Das and Vonderhaar, 1995). Hence, the short form of the receptor, which is expressed in the arcuate nucleus of the hypothalamus, may also play a role in regulating neuronal function.

be excluded from nervous tissue by the specialized tight junctions between vascular endothelial cells in the brain that form the 'blood-brain barrier' (Nilsson et al., 1992). The arcuate nucleus-median eminence region has an incomplete blood-brain barrier, so blood-borne prolactin may have direct access to dopaminergic neurones in this region for negative feedback. In addition, there is clear evidence that systemic prolactin gains access to the 


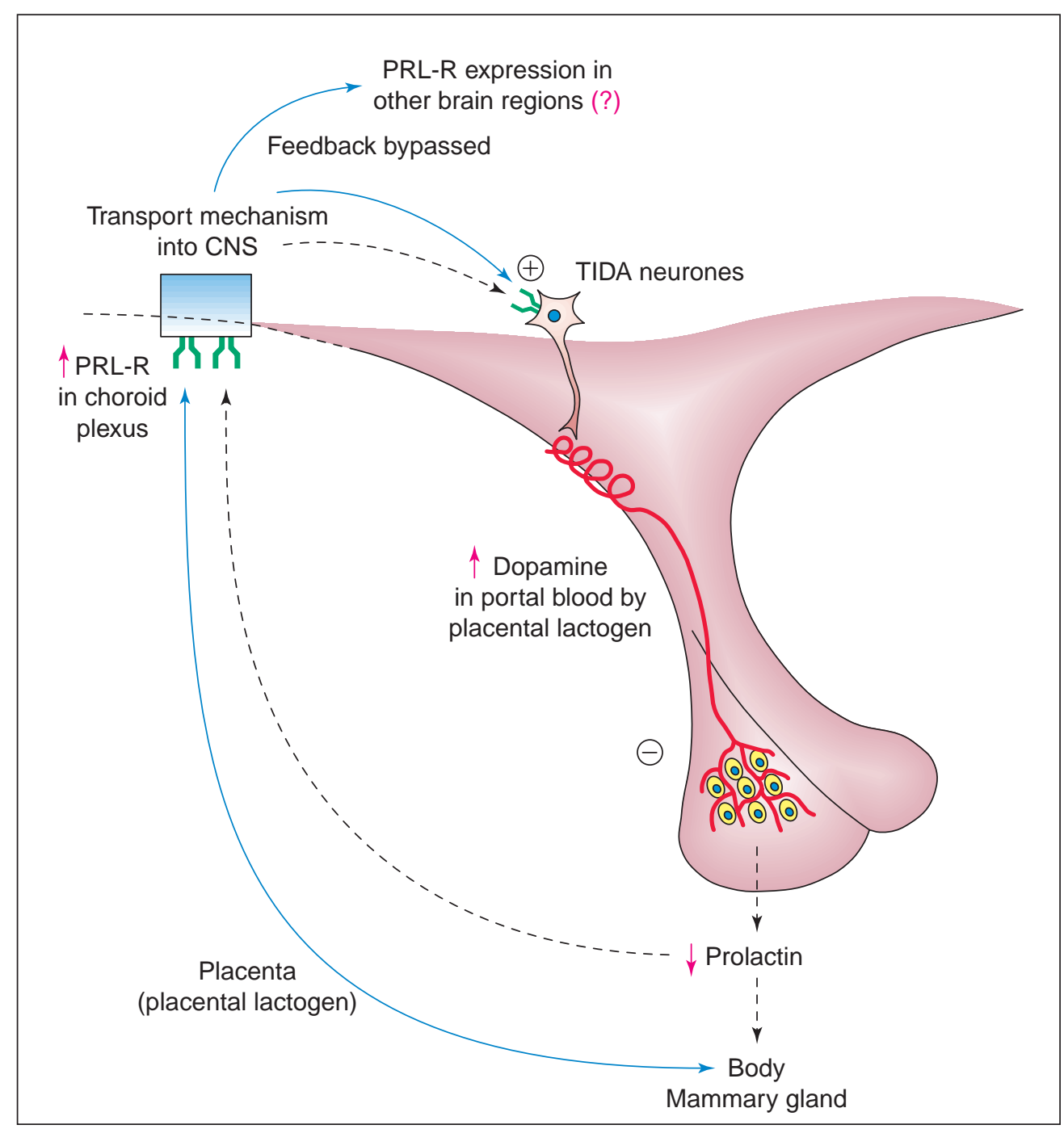

Fig. 2. Neuroendocrine regulation of prolactin secretion during pregnancy. High concentrations of placental lactogen production activate prolactin receptors (PRL-R) on tuberoinfundibular dopaminergic (TIDA) neurones, resulting in suppression of pituitary prolactin secretion. Because it is not regulated by negative feedback, there is the potential for placental lactogen to regulate several other brain regions, although there has been little study of expression of prolactin receptors in the brain during pregnancy. There is increased expression of prolactin receptors in the choroid plexus, and this is likely to be involved in increased transport of prolactin into the brain.

cerebrospinal fluid (CSF), from where it can diffuse to numerous brain regions (Nicholson et al., 1980). Transportation of prolactin into the CSF involves a saturable, carriermediated process (Walsh et al., 1987), involving prolactin binding sites in the choroid plexus (Walsh et al., 1978). The choroid plexus contains fenestrated capillaries, but maintains a blood-CSF barrier by means of continuous tight junctions between the choroid plexus epithelial cells (Nilsson et al., 1992). Hence, blood-borne prolactin would have ready access to the choroid plexus epithelial cells, which express both the short and long forms of the prolactin receptor (Pi and Grattan, 1998a). However, the precise mechanism by which the prolactin receptor mediates translocation of prolactin across this epithelial layer into the CSF, has not been determined.

An account of prolactin actions on the brain would not be complete without acknowledging that there is evidence of prolactin production by neurones. Prolactin of brain origin has been detected in a variety of brain regions, including the hypothalamus, and prolactin mRNA has also been identified in brain tissue. Therefore, it is possible that some of the behavioural effects ascribed to prolactin result from the activity of prolactin-containing peptidergic neurones (for a review, see Dutt et al., 1994). 


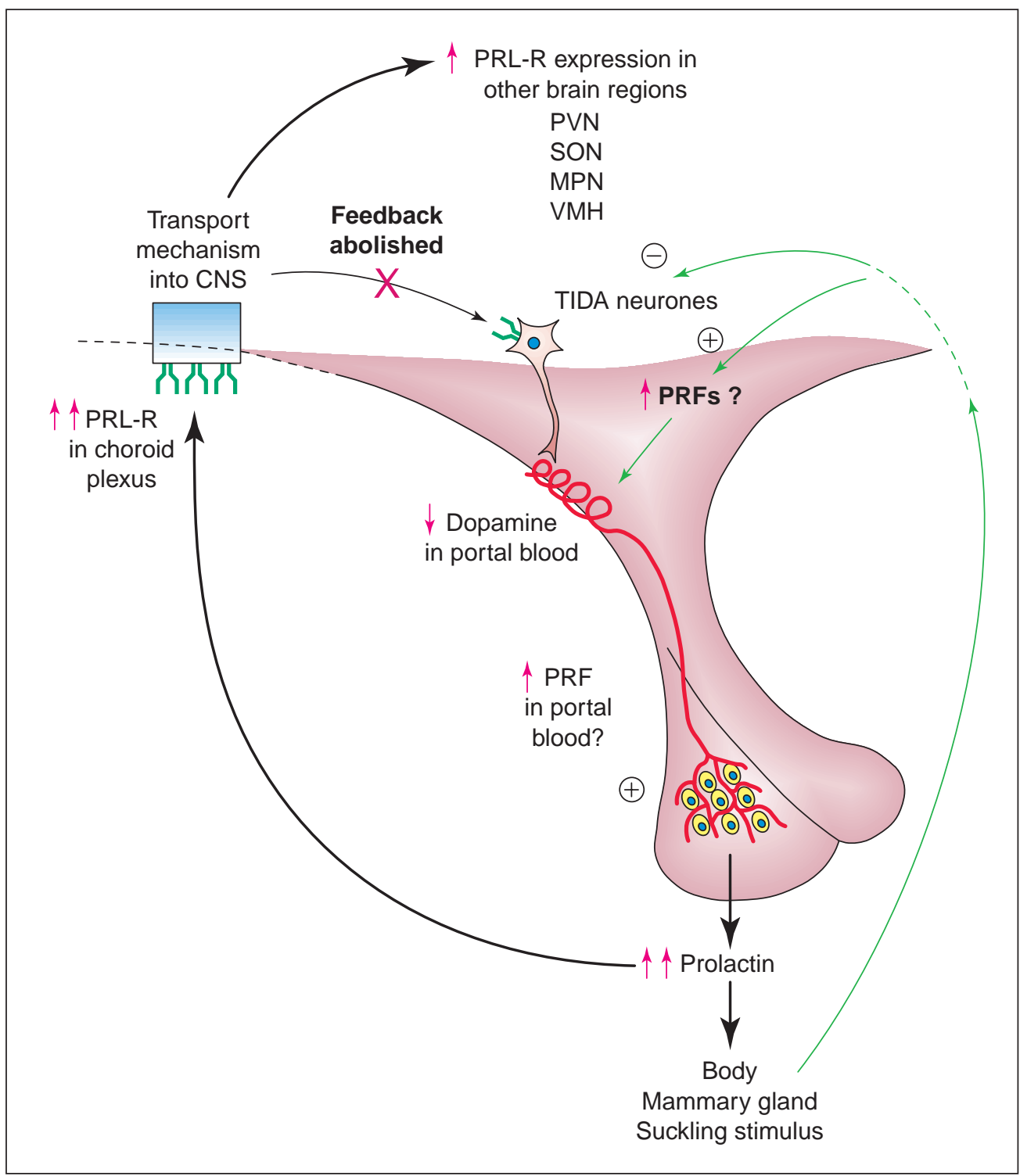

Fig. 3. Neuroendocrine regulation of prolactin secretion during lactation. The suckling stimulus induces increased prolactin secretion by reducing activity of tuberoinfundibular dopaminergic (TIDA) neurones, and possibly also by stimulating one or more prolactin-releasing factors. The normal negative feedback mechanism is abolished, so that prolactin release can be maintained unimpeded by a regulatory feedback mechanism. There is increased expression of prolactin receptors (PRL-R) in the choroid plexus, which is likely to be involved in increased transport of prolactin into the brain. There is increased expression of prolactin receptors throughout the hypothalamus, indicating widespread central actions of prolactin during lactation. MPN: medial preoptic nucleus; PVN: paraventricular nucleus; SON: supraoptic nucleus; VMH: ventromedial hypothalamic nucleus.

\section{Changes in prolactin receptor expression in the brain during pregnancy and lactation}

Prolactin receptor expression has been described in the choroid plexus and hypothalamus using immunohistochemistry (Roky et al., 1996; Pi and Grattan, 1998a,b) and in situ hybridization (Chiu and Wise, 1994; Bakowska and Morrell, 1997). In male and non-pregnant female rats, prolactin receptors are expressed in the arcuate, periventricular and medial preoptic nuclei of the hypothalamus ( $\mathrm{Pi}$ and Grattan, 1999a), and in oestrogen-treated ovariectomized rats, prolactin receptor expression is also observed in the supraoptic and suprachiasmatic nuclei (Pi and Grattan, 1998b). Most of the neurones in the arcuate nucleus that contain prolactin receptor are tyrosine hydroxylase-positive (Grattan, 2001), and represent the TIDA neurones involved in negative 


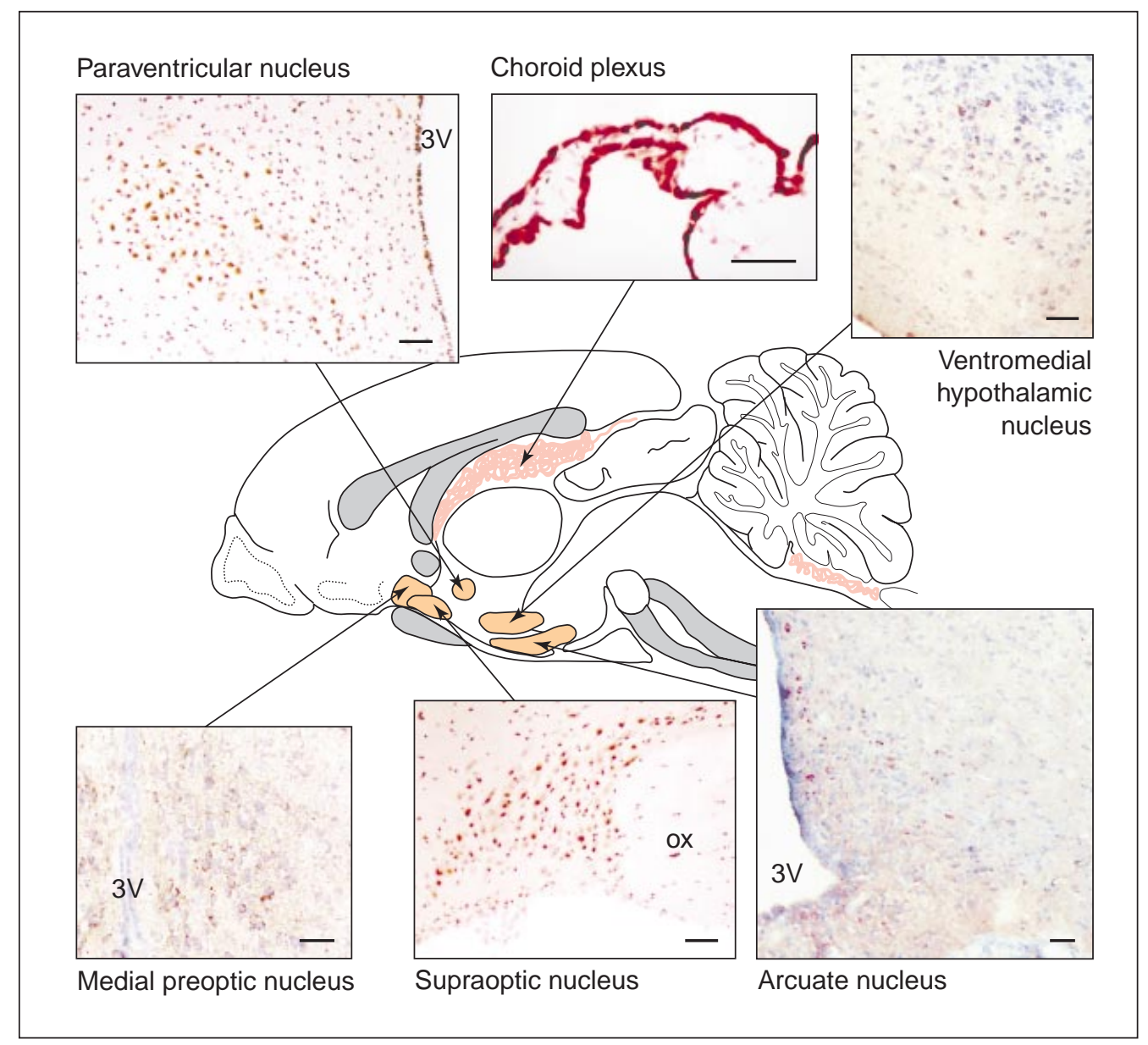

Fig. 4. Brain regions expressing prolactin receptors during lactation in rats. Representative coronal sections have been immunostained as described by Pi and Grattan (1999a) and visualized with 3,3' diaminobenzidene (DAB) (brown immunoreactivity) counterstained with haematoxylin (paraventricular and supraoptic nuclei and choroid plexus) or 3-amino-9-ethylcarbazole (AEC) (red immunoreactivity) counterstained with toluidine blue (medial preoptic, ventromedial hypothalamic and arcuate nuclei). $3 \mathrm{~V}$ : third ventricle; ox: optic chiasm. Scale bars represent $100 \mu \mathrm{m}$.

feedback regulation of prolactin secretion (Fig. 1). Neurochemical identity of neurones in other brain regions that contain prolactin receptor is unknown at present. In most of these hypothalamic nuclei, there is a significant increase in the number of neurones immunoreactive to prolactin receptor during lactation (Pi and Grattan, 1999a). Moreover, some hypothalamic nuclei, including the paraventricular and ventromedial nuclei that do not express prolactin receptor protein in non-pregnant rats, contain significant amounts of prolactin receptor immunoreactivity during lactation (Fig. 4). A similar increase in both the short and long forms of prolactin receptor mRNA in the choroid plexus and a variety of preoptic and hypothalamic nuclei also occurs during lactation (Pi and Grattan, 1999b,c). Hence, there appears to be a marked upregulation of prolactin receptor expression in the hypothalamus during lactation (Fig. 3).

A marked increase in prolactin receptor mRNA expression occurs in the choroid plexus during pregnancy (Sugiyama et al., 1996), and significant increases in both the long and short forms of the prolactin receptor mRNA occur between day 7 and day 14 of pregnancy, persist throughout pregnancy and lactation, and return to basal concentrations after weaning (R. A. Augustine, I. C. Kokay and D. R. Grattan, unpublished). This observation is consistent with the contention that transport of prolactin into the brain is increased during pregnancy and lactation (Figs 2 and 3). In situ hybridization has been used to demonstrate that concentrations of the long form prolactin receptor mRNA in the medial preoptic nucleus increase significantly during late pregnancy compared with early pregnancy (Bakowska and Morrell, 1997).

The mechanisms regulating increased expression of prolactin receptors in the brain of pregnant or lactating rats are not known. There is evidence that oestrogen induces an increase in prolactin receptor expression (Shamgochian et al., 1995), but oestrogen concentrations are low during most of pregnancy and lactation. Prolactin itself may mediate 


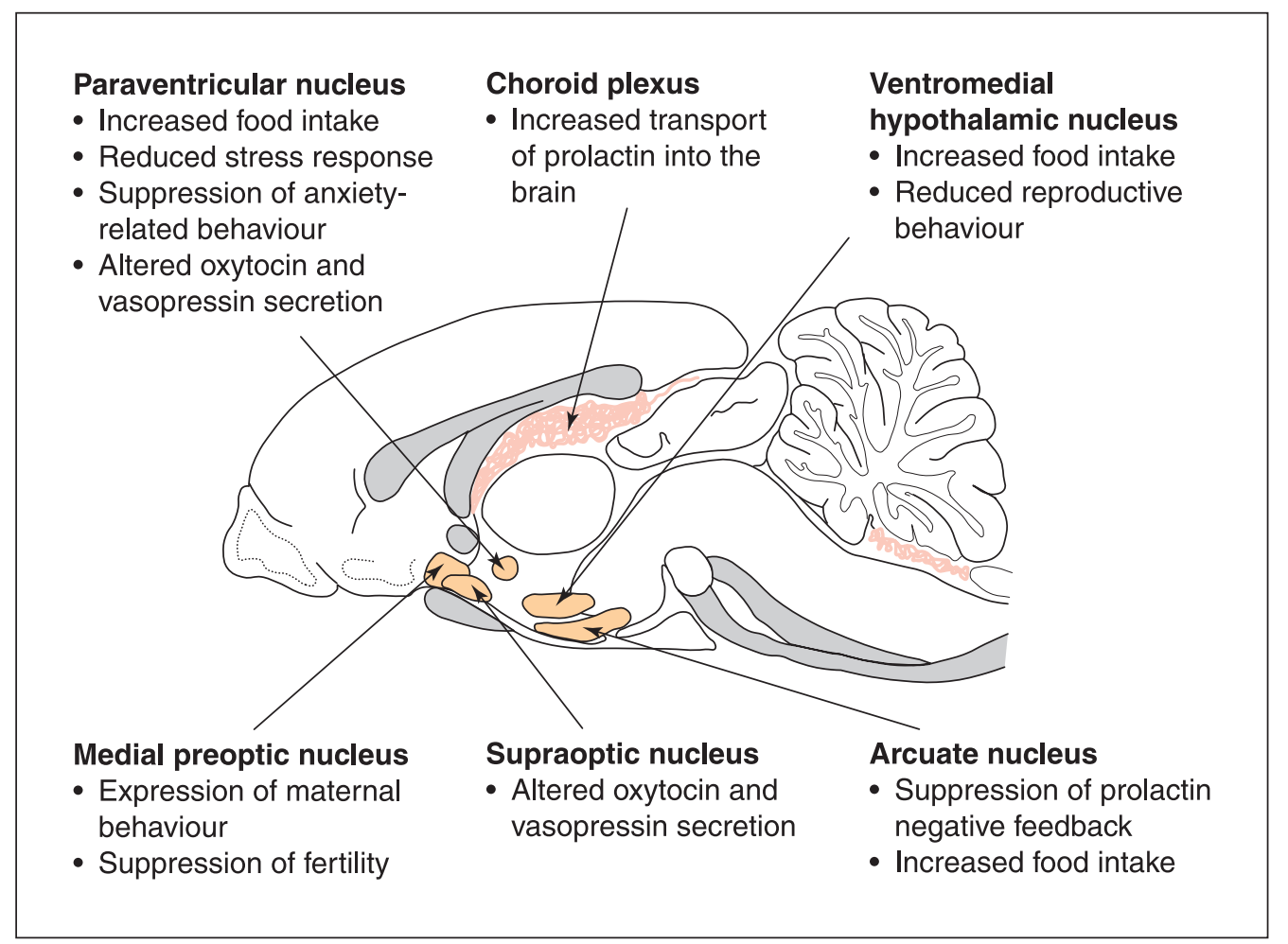

Fig. 5. Summary of the possible influence of prolactin on neuroendocrine and neurobiological adaptations to pregnancy and lactation, depicting the major hypothalamic regions thought to be involved. Prolactin receptors are expressed in all of these regions during lactation.

an upregulation of its receptors (Muccioli and Di Carlo, 1994), as occurs in other tissues. It is probable that hormonal changes of pregnancy, such as the high progesterone concentrations, prolonged increases in placental then pituitary lactogens, and the increasing oestrogen: progesterone ratio before parturition, play a role in stimulating the expression of prolactin receptors during pregnancy and lactation. The increased prolactin receptor expression during lactation appears to result from the combined stimulatory effects of suckling-induced hyperprolactinaemia, and the neural input from the suckling stimulus per se (Pi and Voogt, 2001).

\section{Significance of prolactin receptors in the central nervous system for behaviour}

The evidence presented above can be summarized by making two major points: (1) high concentrations of prolactin or placental lactogen are maintained in the blood throughout pregnancy and lactation; and (2) there is a marked upregulation of prolactin receptor expression in the choroid plexus and hypothalamus during pregnancy and lactation. These data indicate that prolactin exerts important and relatively widespread actions on hypothalamic function during pregnancy and lactation. Certain additional evidence needs to be provided to substantiate such a role for prolactin: specifically, demonstration that: (1) specific regions of the brain involved in mediating pregnancy- or lactationspecific functions express prolactin receptors; (2) pregnancyor lactation-specific neuronal functions are regulated by prolactin in an appropriate manner; and (3) elimination of prolactin signalling, for example through use of gene knockout strategies, or immunoneutralization of prolactin or specific receptor antagonists prevent the pregnancy- or lactation-specific function.

The discussion below examines available evidence on these issues with respect to several pregnancy- or lactationspecific neuronal functions (for summary, see Fig. 5).

\section{Maternal behaviour}

Perhaps the most clearly defined behavioural change occurring during pregnancy and lactation is the onset and maintenance of maternal behaviour. The principal hypothalamic region involved in regulation of this behaviour appears to be the medial preoptic nucleus (Numan, 1994). Prolactin receptors are expressed in this nucleus, and expression is increased during pregnancy and lactation (Bakowska and Morrell, 1997; Pi and Grattan, 1999a,c). Administration of prolactin to appropriately steroid-primed nulliparous rats significantly reduces the latency to onset of maternal behaviour (Bridges et al., 1990), whereas blocking 
prolactin secretion with bromocriptine (Bridges et al., 1990) or blocking prolactin signalling by administration of a prolactin receptor antagonist (Bridges et al., 2001) significantly delays the onset of maternal behaviour. These stimulatory actions of prolactin on maternal behaviour can be mimicked by placental lactogen (Bridges et al., 1996). Animals lacking a functional prolactin receptor exhibit profound deficits in expression of maternal care (Lucas et al., 1998), clearly demonstrating a functional role for prolactin in mediating this process. Animals with a disrupted prolactin gene exhibit some maternal behaviour (Horseman et al., 1997), presumably mediated through activation of prolactin receptors by placental lactogen. Consistent with what is known about the neuronal circuitry regulating maternal behaviour, it appears that the action of prolactin or placental lactogen to stimulate maternal behaviour is exerted in the medial preoptic nucleus (Bridges et al., 1997).

\section{Appetite and food intake}

Lactation is associated with marked hyperphagia (Moore and Brasel, 1984). Appetite and food intake are regulated by a homeostatic mechanism involving a complex hypothalamic circuitry, including the paraventricular, ventromedial and arcuate nuclei (Elmquist et al., 1999). All of these nuclei contain neurones that express prolactin receptors during lactation. Feeding and appetite are stimulated in response to hyperprolactinaemia (Noel and Woodside, 1993), an effect that may be mediated within the paraventricular nucleus (Sauvé and Woodside, 2000). Although initial analyses of prolactin receptor-deficient mice had indicated that prolactin may not play a major role in regulation of body weight in non-pregnant animals (Bole-Feysot et al., 1998), it has been reported more recently that these mice do exhibit lower body weight and reduced fat mass compared with wild-type controls, consistent with the hypothesis that prolactin has a long-term role in the regulation of body weight (Freemark et al., 2001). The upregulation of prolactin receptor expression in lactating rats in the various hypothalamic nuclei associated with appetite regulation may enable a lactating female to be significantly more sensitive than a non-pregnant female to the orexigenic effects of prolactin. Hence, hyperprolactinaemia may play an important role in the hyperphagia of pregnancy and lactation (Moore and Brasel, 1984).

\section{Stress response and anxiety}

The acute stress response is attenuated markedly during late pregnancy (Neumann et al., 1998) and lactation (Lightman, 1992). Hyperprolactinaemia causes a similar decrease in the acute stress response (Carter and Lightman, 1987; Torner et al., 2001), an effect that is prevented by blockade of prolactin signalling using central administration of antisense oligonucleotides directed against the prolactin receptor (Torner et al., 2001). The site of action of prolactin in mediating this action is not known, but is likely to involve the paraventricular nucleus and the hypothalamic- pituitary-adrenal (HPA) axis. Lactation is also associated with marked reductions in anxiety (Picazo and FernandezGuasti, 1993; Toufexis et al., 1999). Anxiety is a complex neurological trait, but has been linked with activity of the HPA stress axis. In both males and non-pregnant female rats, prolactin has dose-dependent anxiolytic actions (Torner et al., 2001). As observed for prolactin-induced suppression of the stress response, the anxiolytic action of prolactin is prevented by administration of antisense oligonucleotides against the prolactin receptor, resulting in increased anxietyrelated behaviour. Hence, prolactin acts as an endogenous anxiolytic, with the ability to reduce the magnitude of the acute stress response. Therefore, increased concentrations of prolactin during lactation, coupled with increased expression of prolactin receptors in the paraventricular nucleus, may contribute to the suppression of the stress response during lactation, perhaps by altering the stress response to respond only to factors relevant in the lactating state.

\section{Oxytocin and vasopressin secretion}

The magnocellular nuclei (paraventricular and supraoptic nuclei) undergo extensive remodelling during pregnancy and lactation (Hatton and Li, 1998), which is associated with increased expression of oxytocin and vasopressin mRNA (Van Tol et al., 1988). Prolactin receptors have been observed in both oxytocin and vasopressin neurones during late pregnancy and lactation (M. R. Summerfield and D. R. Grattan, unpublished). Prolactin influences oxytocin secretion (Sarkar, 1989; Parker et al., 1991) and expression of oxytocin mRNA (Ghosh and Sladek, 1995) in neurones of these nuclei, and hence may play a role in the activation of these neurones during late pregnancy.

\section{Fertility}

During lactation, the female reproductive cycle is interrupted, and fertility is suspended. This effect is critically dependent on the frequency and intensity of suckling episodes, and is caused by the suppression of pulsatile secretion of LH from the anterior pituitary gland. It is likely that the suckling-induced suppression of fertility is mediated by inhibition of $\mathrm{GnRH}$ neurones in the rostral hypothalamus (McNeilly, 1994). Hyperprolactinaemia inhibits gonadotrophin secretion in a number of conditions. Such an effect may be mediated directly on $\mathrm{GnRH}$ neurones, or indirectly by means of prolactin-sensitive afferent neurones. It is not known whether $\mathrm{GnRH}$ neurones contain prolactin receptors, although the immortalized GT1 cell line, derived from $\mathrm{GnRH}$ neurones, does appear to be inhibited directly by prolactin through a prolactin receptor-mediated mechanism (Milenkovic et al., 1994). In lactating rats, there is increased expression of prolactin receptors in parts of the hypothalamus where $\mathrm{GnRH}$ neurones are found, such as the medial preoptic and ventrolateral preoptic nuclei $(\mathrm{Pi}$ and Grattan, 1999a,c). Therefore, it is possible that prolactin is involved in the suckling-induced suppression of fertility during lactation. 


\section{Feedback regulation of prolactin secretion}

The major function of prolactin in the arcuate nucleus in non-pregnant animals is the feedback regulation of TIDA neurones. This feedback system is suppressed during late pregnancy (Grattan and Averill, 1995) and lactation (Arbogast and Voogt, 1996), and the TIDA neurones are markedly less responsive to prolactin than they are in nonpregnant animals. The development of a prolactin-resistant state is an important neuroendocrine adaptation during lactation, because it allows hyperprolactinaemia to be unopposed by a compensatory feedback mechanism (Fig. 3). These changes are essential for maintenance of lactational competency. The role of prolactin in altering its own feedback pathway is not clear. The failure of feedback activation of TIDA neurones does not appear to involve a downregulation of prolactin receptors, as prolactin receptor expression increases in the arcuate nucleus during lactation ( $\mathrm{Pi}$ and Grattan, 1999a). Therefore, it is possible that there is an alteration in post-receptor mechanisms in the TIDA neurones during late pregnancy and lactation. Alternatively, there may be activation of an inhibitory afferent pathway, suppressing TIDA neuronal activity even in the face of high concentrations of prolactin.

\section{Future research directions}

Much work is still required to characterize fully the functions of prolactin in the brain during pregnancy and lactation. Evidence that prolactin gains access to the brain via a carrier-mediated transport system is compelling, but the role of prolactin receptors in the transport of prolactin into the CSF across choroid plexus epithelial cells is not clear. Such a function is not typical of the cytokine family of membrane bound receptors, and it is possible that another transporter protein is involved. Hormones capable of activating the prolactin receptor are present in high concentrations throughout pregnancy and lactation. Initially, this prolactin receptor activation is due to the presence of placental lactogen, later, pituitary prolactin secretion is reinitiated as a result of the suppression of the negative feedback pathway. The mechanism causing downregulation of prolactin signalling in TIDA neurones, while signalling in other neuronal populations is maintained or increased, remains to be determined. During lactation, the suckling stimulus provides further impetus for prolactin secretion and high prolactin concentrations are maintained. The pathways mediating this suckling-induced prolactin secretion, including the possible role of prolactin-releasing factors, are still unknown. Prolactin receptor concentrations in the hypothalamus are increased markedly during pregnancy and lactation, but it is still not clear what specific signals differentially regulate prolactin receptor expression in different neuronal populations.

The neuroendocrine and neurobiological adaptations to pregnancy and lactation represent an intriguing and important example of hormone-induced plasticity within the adult brain. There are now multiple lines of evidence indicating a role of prolactin in regulating this plasticity in the maternal hypothalamus. Prolactin receptors are expressed in specific hypothalamic regions, and their expression is increased during lactation. Manipulations of prolactin signalling result in predictable changes in hypothalamic function, consistent with the changes observed during pregnancy and lactation. Do these observations prove that prolactin is actively involved in regulating a wide range of hypothalamic functions during lactation? It seems unlikely that a single hormone could control such a complex array of neuronal networks. A more reasonable interpretation might be that prolactin is acting as the neuroendocrine signal that informs the brain of the reproductive state. Many other factors would be involved in regulating hypothalamic function during pregnancy and lactation, and there could be quite complex interactions between these factors, but the common role of prolactin would be to alter the pattern of neuronal responses into those suitable for the lactating state. Such a role would complement its critical functions within the mammary gland, with both the body and the brain using a common signal.

\section{References}

Key references are identified by asterisks.

Andrews ZB, Kokay IC and Grattan DR (2001) Dissociation of prolactin secretion from tuberoinfundibular dopamine activity in late pregnant rats Endocrinology 142 2719-2724

Arbogast LA and Voogt JL (1996) The responsiveness of tuberoinfundibular dopaminergic neurons to prolactin feedback is diminished between early lactation and midlactation in the rat Endocrinology 137 47-54

Bakowska JC and Morrell JI (1997) Atlas of the neurons that express mRNA for the long form of the prolactin receptor in the forebrain of the female rat Journal of Comparative Neurology 386 161-177

Bole-Feysot C, Goffin V, Edery M, Binart N and Kelly PA (1998) Prolactin (PRL) and its receptor actions, signal transduction pathways and phenotypes observed in PRL receptor knockout mice Endocrine Reviews 19 225-268

*Bridges RS, Numan M, Ronsheim PM, Mann PE and Lupini CE (1990) Central prolactin infusions stimulate maternal behavior in steroidtreated, nulliparous female rats Proceedings of the National Academy of Sciences USA $878003-8007$

Bridges RS, Robertson MC, Shiu R PC, Friesen HG, Stuer AM and Mann PE (1996) Endocrine communication between conceptus and mother: placental lactogen stimulation of maternal behavior Neuroendocrinology 64 57-64

Bridges RS, Robertson MC, Shiu RP, Sturgis JD, Henriquez BM and Mann PE (1997) Central lactogenic regulation of maternal behavior in rats steroid dependence, hormone specificity, and behavioral potencies of rat prolactin and rat placental lactogen I Endocrinology 138 756-763

Bridges RS, Rigero BA, Byrnes EM, Yang LL and Walker AM (2001) Central infusions of the recombinant human prolactin receptor antagonist, S179D-PRL, delay the onset of maternal behavior in steroid-primed, nulliparous female rats Endocrinology 142 730-739

Carter DA and Lightman SL (1987) Oxytocin responses to stress in lactating and hyperprolactinaemic rats Neuroendocrinology 46 532-537

Chiu S and Wise PM (1994) Prolactin receptor mRNA localization in the hypothalamus by in situ hybridization Journal of Neuroendocrinology 6 191-199

Das R and Vonderhaar BK (1995) Transduction of prolactin's (PRL) growth signal through both long and short forms of the PRL receptor Molecular Endocrinology 9 1750-1759

Dutt A, Kaplitt MG, Kow LM and Pfaff DW (1994) Prolactin, central nervous system and behavior a critical review Neuroendocrinology 59 413-419 
Elmquist JK, Elias CF and Saper CB (1999) From lesions to leptin hypothalamic control of food intake and body weight Neuron 22 221-232

Freeman ME, Kanyicska B, Lerant A and Nagy G (2000) Prolactin structure, function, and regulation of secretion Physiological Reviews 80 1523-1631

Freemark M, Fleenor D, Driscoll P, Binart N and Kelly PA (2001) Body weight and fat deposition in prolactin receptor-deficient mice Endocrinology $142532-537$

Ghosh R and Sladek CD (1995) Role of prolactin and gonadal steroids in regulation of oxytocin mRNA during lactation American Journal of Physiology 269 E76-E84

${ }^{*}$ Grattan D (2001) The actions of prolactin in the brain during pregnancy and lactation Progress in Brain Research 133 153-171

Grattan DR and Averill RL (1995) Absence of short-loop autoregulation of prolactin during late pregnancy in the rat Brain Research Bulletin 36 $413-416$

Grattan DR, Xu JJ, McLachlan MJ, Kokay IC, Bunn SJ, Hovey RC and Davey HW (2001) Feedback regulation of PRL secretion is mediated by the transcription factor, signal transducer, and activator of transcription $5 \mathrm{~b}$ Endocrinology 142 3935-3940

Hatton G I and Li Z H (1998) Neurophysiology of magnocellular neuroendocrine cells: recent advances Progress in Brain Research 119 77-99

Horseman ND, Zhao WZ, Montecinorodriguez E, Tanaka M, Nakashima K, Engle S J, Smith F, Markoff E and Dorshkind K (1997) Defective mammopoiesis, but normal hematopoiesis, in mice with a targeted disruption of the prolactin gene EMBO Journal 16 6926-6935

Kelly MA, Rubinstein M, Asa SL et al. (1997) Pituitary lactotroph hyperplasia and chronic hyperprolactinemia in dopamine D2 receptordeficient mice Neuron 19 103-113

Kelly PA, Binart N, Lucas B, Bouchard B and Goffin V (2001) Implications of multiple phenotypes observed in prolactin receptor knockout mice Frontiers in Neuroendocrinology 22 140-145

Leonard WJ and O'Shea JJ (1998) Jaks and STATs biological implications Annual Review of Immunology 16 293-322

Lerant A, Kanyicska B and Freeman ME (2001) Nuclear translocation of STAT5 and increased expression of Fos related antigens (FRAs) in hypothalamic dopaminergic neurons after prolactin administration Brain Research 904 259-269

Lightman SL (1992) Alterations in hypothalamic-pituitary responsiveness during lactation Annals of the New York Academy of Science 652 340-346

*Lucas BK, Ormandy CJ, Binart N, Bridges RS and Kelly PA (1998) Null mutation of the prolactin receptor gene produces a defect in maternal behavior Endocrinology 139 4102-4107

McNeilly AS (1994) Suckling and the control of gonadotropin secretion. In Physiology of Reproduction Vol. 2 pp 1179-1212 Eds E Knobil and J D Neill. Raven Press, New York

Milenkovic L, D'Angelo G, Kelly PA and Weiner RI (1994) Inhibition of gonadotropin hormone-releasing hormone release by prolactin from GT1 neuronal cell lines through prolactin receptors Proceedings of the National Academy of Sciences USA 91 1244-1247

Moore BJ and Brasel JA (1984) One cycle of reproduction consisting of pregnancy, lactation or no lactation, and recovery effects on carcass composition in ad libitum-fed and food-restricted rats Journal of Nutrition 114 1548-1559

Muccioli G and Di Carlo R (1994) Modulation of prolactin receptors in the rat hypothalamus in response to changes in serum concentration of endogenous prolactin or to ovine prolactin administration Brain Research $663244-250$

Neill JD and Nagy GM (1994) Prolactin secretion and its control. In Physiology of Reproduction Vol. 1 pp 1833-1860 Eds E Knobil and JD Neill. Raven Press, New York

Neumann ID, Johnstone HA, Hatzinger M, Liebsch G, Shipston M, Russell JA, Landgraf R and Douglas AJ (1998) Attenuated neuroendocrine responses to emotional and physical stressors in pregnant rats involve adenohypophysial changes Journal of Physiology 508 289-300

Nicholson G, Greeley GH, Jr, Humm J, Youngblood WW and Kizer JS (1980) Prolactin in cerebrospinal fluid a probable site of prolactin autoregulation Brain Research 190 447-457

Nilsson C, Lindvall-Axelsson M and Owman C (1992) Neuroendocrine regulatory mechanisms in the choroid plexus-cerebrospinal fluid system Brain Research Reviews 17 109-138
Noel MB and Woodside B (1993) Effects of systemic and central prolactin injections on food intake, weight gain, and estrous cyclicity in female rats Physiology and Behaviour 54 151-154

Numan M (1994) A neural circuitry analysis of maternal behavior in the rat Acta Paediatrica Supplement 397 19-28

Parker SL, Armstrong WE, Sladek CD, Grosvenor CE and Crowley WR (1991) Prolactin stimulates the release of oxytocin in lactating rats evidence for a physiological role via an action at the neural lobe Neuroendocrinology 53 503-510

Pi XJ and Grattan DR (1998a) Differential expression of the two forms of prolactin receptor mRNA within microdissected hypothalamic nuclei of the rat Molecular Brain Research 59 1-12

Pi XJ and Grattan DR (1998b) Distribution of prolactin receptor immunoreactivity in the brain of estrogen-treated ovariectomized rats Journal of Comparative Neurology 394 462-474

*Pi XJ and Grattan DR (1999a) Increased prolactin receptor immunoreactivity in the hypothalamus of lactating rats Journal of Neuroendocrinology 11 693-705 [published erratum appears in Journal of Neuroendocrinology 12 97-98]

Pi XJ and Grattan DR (1999b) Increased expression of both short and long forms of prolactin receptor mRNA in hypothalamic nuclei of lactating rats Journal of Molecular Endocrinology 23 13-22

Pi XJ and Grattan DR (1999c) Expression of prolactin receptor mRNA is increased in the preoptic area of lactating rats Endocrine 11 91-98

Pi XJ and Voogt JL (2001) Mechanisms for suckling-induced changes in expression of prolactin receptor in the hypothalamus of the lactating rat Brain Research 891 197-205

Picazo O and Fernandez-Guasti A (1993) Changes in experimental anxiety during pregnancy and lactation Physiology and Behaviour 54 295-299

Roky R, Paut-Pagano L, Goffin V, Kitahama K, Valatx JL, Kelly PA and Jouvet $\mathbf{M}$ (1996) Distribution of prolactin receptors in the rat forebrain Immunohistochemical study Neuroendocrinology 63 422-429

Sarkar DK (1989) Evidence for prolactin feedback actions on hypothalamic oxytocin, vasoactive intestinal peptide and dopamine secretion Neuroendocrinology 49 520-524

Sauvé D and Woodside B (2000) Neuroanatomical specificity of prolactininduced hyperphagia in virgin female rats Brain Research 868 306-314

Selmanoff M and Gregerson K A (1985) Suckling decreases dopamine turnover in both medial and lateral aspects of the median eminence in the rat Neuroscience Letters $\mathbf{5 7}$ 25-30

Shamgochian MD, Avakian C, Truong NH, Stone S, Tang KT and DeVito WJ (1995) Regulation of prolactin receptor expression by estradiol in the female rat brain Neuroreport 6 2537-2541

Soares MJ, Muller H, Orwig KE, Peters TJ and Dai G (1998) The uteroplacental prolactin family and pregnancy Biology of Reproduction $\mathbf{5 8}$ 273-284

Sugiyama T, Minoura H, Toyoda N, Sakaguchi K, Tanaka M, Sudo S and Nakashima K (1996) Pup contact induces the expression of long form prolactin receptor mRNA in the brain of female rats Effects of ovariectomy and hypophysectomy on receptor gene expression Journal of Endocrinology 149 335-340

Torner L, Toschi N, Pohlinger A, Landgraf R and Neumann ID (2001) Anxiolytic and anti-stress effects of brain prolactin Improved efficacy of antisense targeting of the prolactin receptor by molecular modeling Journal of Neuroscience 21 3207-3214

Toufexis DJ, Rochford J and Walker CD (1999) Lactation-induced reduction in rats' acoustic startle is associated with changes in noradrenergic neurotransmission Behaviour and Neuroscience 113 176-184

Tucker H (1994) Lactation and its hormonal control. In Physiology of Reproduction Vol. 2 pp 1065-1098 Eds E Knobil and J D Neill. Raven Press, New York

Van Tol HH, Bolwerk EL, Liu B and Burbach JP (1988) Oxytocin and vasopressin gene expression in the hypothalamo-neurohypophyseal system of the rat during the estrous cycle, pregnancy, and lactation Endocrinology 122 945-951

Walsh RJ, Posner BI, Kopriwa BM and Brawer JR (1978) Prolactin binding sites in the rat brain Science 201 1041-1043

*Walsh RJ, Slaby FJ and Posner BI (1987) A receptor-mediated mechanism for the transport of prolactin from blood to cerebrospinal fluid Endocrinology 120 1846-1850 